Pacific Journal of Mathematics

ENTIRE FUNCTIONS OF SEVERAL VARIABLES WITH
ALGEBRAIC DERIVATIVES AT CERTAIN ALGEBRAIC POINTS 


\title{
ENTIRE FUNCTIONS OF SEVERAL VARIABLES WITH ALGEBRAIC DERIVATIVES AT CERTAIN ALGEBRAIC POINTS ${ }^{1}$
}

Fred Gross

\begin{abstract}
The purpose of this paper is to extend certain theorems on the arithmetic properties of analytic functions due to Straus to functions of several variables.
\end{abstract}

Numerous papers have been written on the arithmetic properties of analytic functions (e.g., Straus [7], Buck [1], Kakeya [3], Selberg [5]). The author is not aware of any analogous studies for analytic functions of several variables. Since the generalization from two to several variables involves no new difficulties that are not already encountered in the generalization from one to two variables, we shall for the sake of simplicity, restrict our discussion to functions of two variables.

2. Preliminaries. We begin with a generalization of order and type.

DEFINITION 1. Let $f\left(z_{1}, z_{2}\right)$ be an entire function of the two variables. Let $M\left(r_{1}, r_{2}\right)=M(r)$ denote the maximum value of $|f|$ on the surface given by $\left|z_{i}\right|=r_{i}(i=1,2) .\left(\rho_{1}, \rho_{2}\right)$ is said to be an order point of $f$, if for any $\varepsilon>0$, as $r_{1}+r_{2}$ approaches infinity

$$
M(r) / \exp \left(r_{1}^{\rho_{1}+\varepsilon}+r_{2}^{o_{2}+\varepsilon}\right)
$$

is bounded, while

$$
M(r) / \exp \left(r_{1}^{o_{1}}+r_{2}^{\rho_{2}-\varepsilon}\right)
$$

and

$$
M(r) / \exp \left(r_{1}^{\rho_{1}-\varepsilon}+r_{2}^{\rho_{2}}\right)
$$

are both unbounded. The set, $\rho$, of all such points $\left(\rho_{1}, \rho_{2}\right)$ is called the order of $f$.

Definition 2. Let $f\left(z_{1}, z_{2}\right)$ be as above and let $\left(\rho_{1}, \rho_{2}\right)$ be one of its order points. $\left(\sigma_{1}, \sigma_{2}\right)$ is said to be a type point of $f$ at $\left(\rho_{1}, \rho_{2}\right)$ if for any $\varepsilon>0$, as $r_{1}+r_{2}$ approaches infinity

${ }^{1}$ In a dissertation written by the author under the direction of Professor E. G. Straus and submitted to U.C.L.A. in July 1962, variations of the results in this paper were proved by a generalization of an argument used by Straus in [7]. The arguments presented here are somewhat briefer. 


$$
M(r) / \exp \left(\left(\sigma_{1}+\varepsilon\right) r_{1}^{\rho_{1}}+\left(\sigma_{2}+\varepsilon\right) r_{2}^{\rho_{2}}\right)
$$

is bounded, while

$$
M(r) / \exp \left(\sigma_{1} r_{1}^{o_{1}}+\left(\sigma_{2}-\varepsilon\right) r_{2}^{o_{2}}\right)
$$

and

$$
M(r) / \exp \left(\left(\sigma_{1}-\varepsilon\right) r_{1}^{\rho_{1}}+\sigma_{2} r_{2}^{o_{2}}\right)
$$

are both unbounded. The set of points, $\sigma_{\rho_{1} \rho_{2}}$, of all such points $\left(\sigma_{1}, \sigma_{2}\right)$ is called the type of $f$ at $\left(\rho_{1}, \rho_{2}\right)$.

For the sake of simplicity, we add the following.

Definition 3. An entire function $f\left(z_{1}, z_{2}\right)$ will be said to have $\left\{\left(\rho_{1}, \sigma_{1}\right),\left(\rho_{2}, \sigma_{2}\right)\right\}$ as an order-type point if $\left(\rho_{1}, \rho_{2}\right)$ is an order point of $f$ and $\left(\sigma_{1}, \sigma_{2}\right)$ is a type point of $f$ at $\left(\rho_{1}, \rho_{2}\right)$. We shall say that $\left(\rho_{i}, \sigma_{i}\right)<$ $(x, y)$ if either $\rho_{i}<x$ or $\rho_{i}=x$ and $\sigma_{i}<y(i=1,2)$.

We state some lemmas whose proofs are contained in [2].

Lemma 1. (Generalized Taylor series.) Let $f\left(z_{1}, z_{2}\right)$ be entire and let $z_{i j}(i=1,2 ; j=1,2, \cdots)$ be two infinite sequences of complex numbers whose terms are bounded. Then one may write

$$
f\left(z_{1}, z_{2}\right)=\sum_{n_{1}=0}^{\infty} \sum_{n_{2}=0}^{\infty} a_{n_{1} n_{2}} \prod_{i=1}^{2} \prod_{j=1}^{n_{i}}\left(z_{i}-z_{i j}\right),
$$

with

$$
a_{n_{1} n_{2}}=\frac{1}{(2 \pi i)^{2}} \int_{|z|=r_{1}} \int_{|z|=r_{2}} \frac{f\left(z_{1}, z_{2}\right) d z_{1} d z_{2}}{\prod_{i=1}^{2} \prod_{j=1}^{n_{i}+-1}\left(z_{i}-z_{i j}\right)}
$$

where

$$
r_{i}>\max _{j}\left|z_{i j}\right| \quad(i=1,2 ; j=1,2, \cdots) .
$$

Proof. Same as Lemma 2.1 in [2].

When $z_{i j}$ is a finite set of integers, $\alpha_{j}\left(j=0,1, \cdots ; k_{1}-1\right)$ and $z_{2 j}$ is a finite set of integers, $\beta_{j}\left(j=0,1, \cdots ; k_{2}-1\right)$ then (1) may be written as

$$
\begin{aligned}
f\left(z_{1}, z_{2}\right) & =\sum_{s=0}^{\infty} \sum_{l=0}^{k_{1}-1} \sum_{t=0}^{\infty} \sum_{h=0}^{k_{2}-1} a_{\left(s k_{1}+l\right)\left(t k_{2}+h\right)}\left(\alpha_{1}-\alpha_{0}\right)^{s+1} \cdots \\
& \left(z_{1}-\alpha_{l-1}\right)^{s+1}\left(z_{1}-\alpha_{l}\right)^{s} \cdots\left(z_{1}-\alpha_{k_{1}-1}\right)^{s}\left(z_{2}-\beta_{0}\right)^{t+1} \cdots \\
& \left(z_{2}-\beta_{k_{2}-1}\right)^{t} .
\end{aligned}
$$


By means of the residue theorem and (2), one obtains

LEMMA 2. If

$$
\partial^{n_{1}+n_{2}} f\left(z_{1}, z_{2}\right) / \partial z_{1}^{n_{1}} \partial z_{2}^{n_{2}}
$$

is integral for $\left(z_{1}, z_{2}\right)=\left(\alpha_{i}, \beta_{j}\right)\left(i=0,1, \cdots, k_{1}-1 ; j=0,1, \cdots, k_{2}-1\right)$ and for all nonnegative integers $n_{1}$ and $n_{2}$, then the coefficients $a_{\left(s k_{1}+l\right)\left(t k_{2} \div l\right)}$ on the right side of (1a) are rational numbers whose denominators divide the least common multiple of the quantities

$$
(s-x) ! \prod_{j=0 ; j \neq m}^{l}\left(\alpha_{m}-\alpha_{j}\right)^{s+1+x_{j}} \prod_{j=l+1 ; j \neq m}^{k_{1}-1}\left(\alpha_{m}-\alpha_{j}\right)^{s+x_{j}}(t-y) !
$$

$$
\prod_{i=0 ; i \neq n}^{h}\left(\beta_{n}-\beta_{i}\right)^{t+1+y_{i}} \prod_{i=h+1 ; i \neq n}^{k_{2}-1}\left(\beta_{n}-\beta_{i}\right)^{t+y_{i}}
$$

$m=0,1, \cdots, k_{1}-1 ; n=0,1, \cdots, k_{2}-1 ;\left\{x_{0}+x_{1}+\cdots+x_{k_{1}-1}=x\right.$, $\left.y_{0}+y_{1}+\cdots+y_{k_{2}-1}=y\right\} ; x=0,1, \cdots, s$ and $y=0,1, \cdots t$.

Proof. See proof of Theorem 3.6 pages 134 and 135 in [2]. An argument almost identical to this gives the following.

Lemma 2A. If the $\alpha^{\prime} s, \beta^{\prime} s$ and partial derivatives in Lemma 2 are algebraic integers, then each of the coefficients is a ratio of two algebraic integers whose denominator is the least common multiple of the expressions (3).

LEMMA 3. Let $f$ and $a_{n_{1} n_{2}}$ be as in Lemma 1 and suppose that $\left\{\left(\rho_{1}, \sigma_{1}\right),\left(\rho_{2}, \sigma_{2}\right\}\right.$ is an order-type point of $f$. Then the inequality

$$
M(r)<\exp \left(r_{1}^{\rho_{1}+\varepsilon}+r_{2}^{\rho_{2}+\varepsilon}\right)
$$

holds for $\varepsilon>0$ and all sufficiently large (depending on $\varepsilon$ ) $r_{1}+r_{2}$ if, and only if, the inequality

$$
\left|a_{n_{1} n_{2}}\right|<\prod_{i=1}^{2} n_{i}^{-n_{i} /\left(\rho_{i}+\varepsilon\right)}
$$

holds for $\varepsilon>0$ and all sufficiently large (depending on $\varepsilon$ ) $n_{1}+n_{2}$. Furthermore, the inequality

$$
M(r)<\exp \left(\left(\sigma_{1}+\varepsilon\right) r_{1}^{o}+\left(\sigma_{2}+\varepsilon\right) r_{2}^{\rho_{2}}\right)
$$

holds for $\varepsilon<0$ and all sufficiently large (depending on $\varepsilon$ ) $r_{1}+r_{2}$ if, and only if, the inequality

$$
\left|a_{n_{1} n_{2}}\right|<\prod_{i=1}^{2}\left(\left(e \rho_{i} \sigma_{i}+\varepsilon\right) / n_{i}\right)^{n_{i} / \rho_{i}}
$$

holds for $\varepsilon>0$ and all sufficiently large (depending on $\varepsilon) r_{1}+r_{2}$.

Proof. The proof of this lemma is entirely analogous to the one 
variable case (see e.g. [6]).

3. Main result. We first consider the case where assumptions are made about the value of the function and its partial derivatives at a single point.

THEOREM 1. Let $f\left(z_{1}, z_{2}\right)$ be an entire function such that

$$
\partial^{n_{1}+n_{2}} f(0,0) / \partial z_{1}^{n_{1}} \partial z_{2}^{n_{2}}=a_{n_{1} n_{2}},
$$

where $\alpha_{n_{1} n_{2}}$ is an algebraic number of degree $\leqq d$ for $n_{1}, n_{2}=0,1, \cdots$. Let $q_{n_{1} n_{2}}$ be a positive rational integer such that $q_{n_{1} n_{2}} \alpha_{n_{1} n_{2}}$ is an algebraic integer. Assume that for some positive numbers $A, B, s_{i}$ and $t_{i}(i=1,2)$ and any positive $\varepsilon$

$$
\overline{\left|\alpha_{n_{1} n_{2}}\right|}=0\left((A+\varepsilon)^{n_{1}+n_{2}} n_{1}^{s_{1} n_{1}} n_{2}^{s_{2} n_{2}}\right.
$$

and

$$
q_{n_{1} n_{2}}=0\left((B+\varepsilon)^{n_{1}+n_{2}} n_{1}^{t_{1} n_{1}} n_{2}^{t_{2} n_{2}}\right) .
$$

Let

$$
\begin{aligned}
& \rho_{i 0}=\left(\left(s_{i}+t_{i}\right)(d-1)+t_{i}+1\right)^{-1} \\
& \sigma_{i 0}=\left(e \rho_{i 0}\right)^{-1}\left(e A^{-(d-1)} B^{-d) o_{i 0}}\right) \quad(i=1,2) .
\end{aligned}
$$

If for some order-type point, $\left\{\left(\rho_{1}, \sigma_{1}\right),\left(\rho_{2}, \sigma_{2}\right)\right\}$, of $f$, there holds

$$
\left(\rho_{i}, \sigma_{i}\right)<\left(\rho_{i 0}, \sigma_{i 0}\right) \quad(i=1,2),
$$

then $f$ is a polynomial.

Proof. We may write

$$
f\left(z_{i}, z_{2}\right)=\sum a_{n_{1} n_{2}} z_{1}^{n_{1}} z_{2}^{n_{2}},
$$

where

$$
\alpha_{n_{1} n_{2}}=\alpha_{n_{1} n_{2}} / n_{1} ! n_{2} !
$$

Furthermore, it follows from the hypotheses of the theorem that

$$
\mid \overline{q_{n_{1} n_{2}} \alpha_{n_{1} n_{2}} \mid}=0\left((A B+\varepsilon)^{n_{1}+n_{2}} n_{1}^{\left(s_{1}+t_{1}\right) n_{1}} n_{2}^{\left(s_{2} \div t_{2}\right) n_{2}}\right) \text {. }
$$

Assume that $f$ is not a polynomial. Since $q_{n_{1} n_{2}} \alpha_{n_{1} n_{2}}$ is an algebraic integer, it follows that for an infinite sequence of pairs $\left(n_{1}, n_{2}\right)$

$$
\mid \text { Norm } q_{n_{1} n_{2}} \alpha_{n_{1} n_{2}} \mid \geqq 1 \text {. }
$$

Consequently, for these $n_{1}$ and $n_{2}$

$$
\left|q_{n_{1} n_{2}} \alpha_{n_{1} n_{2}}\right| \geqq \mid \text { Norm } q_{n_{1} n_{2}} \alpha_{n_{1} n_{2}}\left|\overline{q_{n_{1} n_{2}} \alpha_{n_{1} n_{2}}}\right|^{-(d-1)} .
$$


Thus, from (6), (7) and (9) we obtain

$$
\begin{aligned}
& \mid \text { Norm } q_{n_{1} n_{2}} \alpha_{n_{1} n_{2}} \mid \leqq \frac{\left|\alpha_{n_{1} n_{2}}\right|}{n_{1} ! n_{2} !}\left[0 \left(\prod _ { i = 1 } ^ { 2 } \left((A B+\varepsilon)^{(d-1) n_{i}}\right.\right.\right. \\
& \left.\left.\left.\quad \times(B+\varepsilon)^{n_{i}} e^{-n_{i}} n_{i}^{\left[\left(s_{i}+t_{i}\right)(d-1)+t_{i}+1\right] n_{i}}\right)\right)\right] .
\end{aligned}
$$

On the other hand, it follows from (4) of Lemma 3 that

$$
\frac{\left|\alpha_{n_{1} n_{2}}\right|}{n_{1} ! n_{2} !}<\left|a_{n_{1} n_{2}}\right|<\prod_{i=1}^{2} n_{i}^{-n_{i} /\left(\rho_{i}+\varepsilon\right)}
$$

If for $i=1,2, \rho_{i}<\rho_{i 0}$, then for some positive $\varepsilon$ satisfying $\rho_{i}+\varepsilon<$ $\rho_{i 0}-\varepsilon$ and some positive $\varepsilon_{0}$

$$
n_{i}^{-n_{i} /\left(\rho_{i}+\varepsilon\right)}<n_{i}^{-n_{i}\left[\left(s_{i}+t_{i}\right)(d-1)+t_{i}+1\right]-\varepsilon_{0} n_{i}} \quad(i=1,2) .
$$

From (10), (11) and (12), one easily concludes that for sufficiently large $n_{1}+n_{2}$

$$
\mid \text { Norm } q_{n_{1} n_{2}} \alpha_{n_{1} n_{2}} \mid<1 \text {. }
$$

Thus, in this case, we get a contradiction between (8) and (13).

If $\rho_{i}=\rho_{i 0}$ and $\alpha_{i}<\alpha_{i 0}$ for either $i=1$ or $i=2$ or both, then one can similarly use (5) of Lemma 3 (instead of (4)) together with (10) to again arrive at the contradiction between (8) and (13). This completes the proof of the theorem.

We now proceed to the case where something is known about the value of the function and its partial derivatives at several points.

THEOREM 2. Let $f\left(z_{1}, z_{2}\right)$ be entire and suppose that for all nonnegative integers $n_{1}$ and $n_{2}$

$$
\partial^{n_{1}+n_{2}} f\left(z_{1}, z_{2}\right) / \partial z_{1}^{n_{1}} \partial z_{2}^{n_{2}}
$$

is integral for $\left(z_{1}, z_{2}\right)=\left(a_{i}, b_{j}\right)\left(i=1,2, \cdots, k_{1}, j=1,2, \cdots, k_{2}\right)$ with $a_{i} \neq a_{j}, b_{i} \neq b_{j}$ for $i \neq j$, where $a_{i}$ and $b_{j}$ are integers. If $f$ has an order type point satisfying

$$
\begin{aligned}
& \left(\rho_{1}, \sigma_{1}\right)<\left(k_{1},\left|V\left(a_{j}\right)^{-2}\right|\right) \\
& \left(\rho_{2}, \sigma_{2}\right)<\left(k_{2},\left|V\left(b_{i}\right)^{-2}\right|\right),
\end{aligned}
$$

where $V\left(a_{j}\right)$ and $V\left(b_{j}\right)$ are the Vandermondes of the $a_{j}^{\prime}$ s and $b_{j}^{\prime} s$ respectively, then $f$ is a polynomial.

Proof. By Lemma 1, we may write

$$
f\left(z_{1}, z_{2}\right)=\sum \alpha_{n_{1} n_{2}}\left(z_{1}-a_{1}\right)\left(z_{1}-a_{2}\right) \cdots\left(z_{1}-a_{n_{1}}\right)\left(z_{2}-b_{1}\right) \cdots\left(z_{2}-b_{n_{2}}\right) \text {. }
$$


where $a_{k_{1}+n}=a_{n}$ and $b_{k_{2}+n}=b_{n}(n=1,2, \cdots)$. Using Lemma 2 with $s=\left[n_{1} / k_{1}\right]$ and $t=\left[n_{2} / k_{2}\right]([r]=$ greatest integer less than $r)$, one easily concludes by looking at the expressions (3) that $\alpha_{n_{1} n_{2}}$ is a rational number expressible as $c_{n_{1} n_{2}} / d_{n_{1} n_{2}}, c_{n_{1} n_{2}}$ integers and

$$
d_{n_{1} n_{2}}=\left[n_{1} / k_{1}\right] !\left[n_{2} / k_{2}\right] ! V\left(a_{i}\right)^{2\left[n_{1} / k_{1}\right]} V\left(b_{j}\right)^{2\left[n_{2} / k_{2}\right]} .
$$

If $\rho_{i}<k_{i}(i=1,2)$, then using (4) of Lemma 3, we obtain

$$
\left|c_{n_{1} n_{2}}\right|=\left|\alpha_{n_{1} n_{2}}\right|\left|d_{n_{1} n_{2}}\right|<\prod_{i=1}^{2}\left(n_{i}^{-n_{i} / k_{i}}\left[n_{i} / k_{i}\right] !\left|V_{i}\right|^{\mid\left[n_{i} / k_{i}\right]}\right),
$$

where $V_{1}$ and $V_{2}$ are $V\left(a_{j}\right)$ and $V\left(b_{j}\right)$ respectively.

For sufficiently large $n_{1}+n_{2}$, the right side of (14) is less than 1. Thus, $c_{n_{1} n_{2}}$ and consequently $\alpha_{n_{1} n_{2}}$ must be zero, so that in this case, $f$ must be a polynomial. If $\rho_{i}=k_{i}$ and $\sigma_{i}<V_{i}^{-2}$ for one of the values $i$, then by virtue of (5) Lemma 3

$$
\begin{aligned}
& \left|c_{n_{1} n_{2}}\right|<\left(\left(e k_{i}\left|V_{i}\right|^{-2}+\varepsilon\right) / n_{i}\right)^{n_{i} / k_{i}} \\
& \left.\left[n_{i} / k_{i}\right] ! V_{i}^{2\left[n_{i} / k_{i}\right]}\right) \mid \text { (second factor) } \mid .
\end{aligned}
$$

It is easy to see that the first factor on the right side of (15) is less than 1 for sufficiently large $n_{i}$. The second factor is either of the same form as the first or has the form of the right factors appearing in (14). Thus, in any case the right side of (15) is less than 1 for sufficiently large $n_{1}+n_{2}$ and the theorem follows.

Instead of considering functions with integral values and partial derivatives at the integers one can consider more generally functions whose values and derivatives evaluated at a certain set, $F$, of algebraic numbers are themselves numbers in $F$.

THEOREM 3. Let $f\left(z_{1}, z_{2}\right)$ be an entire function such that

$$
\frac{\partial^{n_{1}+n_{2}} f\left(z_{1}, z_{2}\right)}{\partial z_{1}^{n_{1}} \partial z_{2}^{n_{2}}}
$$

has the values $\alpha_{n_{1} n_{2} i j}$ at the points $\left(z_{1}, z_{2}\right)=\left(\alpha_{i}, \beta_{j}\right) ; i=0, \cdots, k_{1}-1$, $j=0, \cdots, k_{2}-1, \alpha_{0}=\beta_{0}=0 ; \alpha_{i_{1}} \neq \alpha_{i_{2}}, \beta_{i_{1}} \neq \beta_{i_{2}}$ when $i_{1} \neq i_{2}$. Assume that $\alpha_{n_{1} n_{2} i j}, \alpha_{i}$ and $\beta_{j}$ belong to an algebraic number field $K$ of degree $d$ for $n_{1}=0,1, \cdots ; n_{2}=0,1, \cdots ; i=0,1, \cdots, k_{1}-1$ and $j=0,1, \cdots$, $k_{2}-1$. Let

$$
\begin{aligned}
& M_{1}=2 \max _{i} \overline{\left|\alpha_{i}\right|}, \\
& M_{2}=2 \max _{j} \overline{\left|\beta_{j}\right|}
\end{aligned}
$$


and let $c$ be a positive rational integer such that $c \alpha_{i}^{(\nu)}, c \beta_{j}^{(\nu)}$ are algebraic integers for $i=1, \cdots ; k_{1}-1$ and $j=1, \cdots, k_{2}-1$, where $\alpha_{i}^{(\nu)}$, $\beta_{j}^{(\nu)}(\nu=1, \cdots, d)$ are the conjugates of $\alpha_{i}$ and $\beta_{i}$ respectively. Let $q_{n_{1} n_{2}}$ be a positive rational integer such that $q_{n_{1} n_{2}} \alpha_{n_{1} n_{2} i j}$ is an algebraic integer and assume that for some positive reals $A_{1}, s_{1}, s_{2}, B, t_{1}, t_{2}$

$$
\mid \overline{\alpha_{n_{1} n_{2} i j}}=0\left((A+\varepsilon)^{n_{1}+n_{2}} n_{1}^{s_{1} n_{1}} n_{2}^{s_{2} n_{2}}\right)
$$

and

$$
q_{n_{1} n_{2}}=0\left((B+\varepsilon)^{n_{1}+n_{2}} n_{1}^{t_{1} n} n_{2}^{t_{2} n_{2}}\right)
$$

for

$$
i=0,1, \cdots, k_{1}-1 ; j=0,1, \cdots, k_{2}-1 ; n_{1}=0,1, \cdots
$$

and $n_{2}=0,1, \ldots$ Let $\lambda_{i}=2 k_{i}\left(k_{i}-1\right)$,

$$
\rho_{i 0}=k_{i}\left[\left(d t_{i}+(d-1) s_{i}\right) k_{i}+d\right]^{-1}
$$

and

$$
\begin{aligned}
& \sigma_{i 0}=\left(e \rho_{i 0}\right)^{-1}\left(\left(k_{i} e\right)^{d} M_{i}^{\lambda_{i}(d-1)}\right)^{\rho_{i} / k_{i}} \\
& \left(A^{(d-1)} B^{d}\left|V_{i}\right|^{2 / k_{i}} e^{d \lambda_{i} / k_{i}}\right)^{-\rho_{i 0}}
\end{aligned}
$$

for $i=1,2$.

If $f$ has an order-type point satisfying

$$
\left(\rho_{i}, \sigma_{i}\right)<\left(\rho_{i 0}, \sigma_{i 0}\right)
$$$$
(i=1,2),
$$

then $f$ is a polynomial.

Proof. Let $f\left(z_{1}, z_{2}\right)$ be given by (1). If $\alpha_{n_{1} n_{2} i j}, \alpha_{i}$ and $\beta_{j}$ were algebraic integers, then applying Lemma $2 \mathrm{~A}$ one would be able to express the coefficients of the series as a ratio of two algebraic integers $c_{n_{1} n_{2}} / d_{n_{1} n_{2}}$ and one would get an upper bound for $\left|c_{n_{1} n_{2}}\right|$ as in the proof of the previous theorem. From the hypotheses of the theorem one can also get an upper bound for $\left|c_{n_{1} n_{2}}\right|$ and subsequently arrive at the conclusion that $\mid$ Norm $c_{n_{1} n_{2}} \mid<1$ for sufficiently large $n_{1}+n_{2}$. Though in our case $\alpha_{n_{1} n_{2} i j}, \alpha_{i}, \beta_{j}$ are not algebraic integers, multiplication by the appropriate rational integers effectively reduces it to the simpler case just mentioned.

For the sake of convenience let us also express $f$ in the equivalent form (1a) with $s=\left[n_{1} / k_{1}\right]$ and $t=\left[n_{2} / k_{2}\right]$. From the second equation on page 135 of [2] one can easily verify that one may write

$$
\begin{aligned}
\frac{c_{n_{1} n_{2}}}{d_{n_{1} n_{2}}} & =q_{n_{1} n_{2}} a_{n_{1} n_{2}} c^{\left(\lambda_{1}\left[n_{1} / k_{1}\right]+\lambda_{2}\left[n_{2} / k_{2}\right]\right)} \\
& =q_{\left(s k_{1}+l\right)\left(t k_{2}+h\right)} c^{\left(\lambda_{1} s+\lambda_{2} t\right)} a_{\left(s k_{1}+l\right)\left(t k_{2}+h\right)}
\end{aligned}
$$


with

$$
\left|d_{n_{1} n_{2}}\right|<\prod_{i=1}^{2}\left|V_{i}\right|^{2\left[n_{i} / k_{i}\right]}\left[\frac{n_{i}}{k_{i}}\right] \text { ! }
$$

and $c_{n_{1} n_{2}}$ an algebraic integer of the form

$$
\sum I_{l} \gamma_{l} \eta_{l}
$$

where $I_{l}$ is a positive rational integer satisfying for all $l$

$$
I_{l}<4 \prod_{i=1}^{2}\left(\left[\frac{n_{i}}{k_{i}}\right]^{k_{i}+2}\left[\frac{n_{i}}{k_{i}}\right] !\right) c^{\lambda_{1}\left[n_{1} / k_{1}\right]+\lambda_{2}\left[n_{2} / k_{2}\right]} O\left((B+\varepsilon)^{n_{1}+n_{2}} n_{1}^{t_{1} n_{1}} n_{2}^{t_{2} n_{2}}\right) ;
$$

the $\gamma_{l}$ are products of at most $\lambda_{1} / 2$ terms of the form $\left(\alpha_{i}-\alpha_{j}\right)^{u_{i j}}$ and at most $\lambda_{2} / 2$ terms of the form $\left(\beta_{i}-\beta_{j}\right)^{r_{i j}}$ with

$$
u_{i j}<2\left[\frac{n_{1}}{k_{1}}\right] v_{i j}<2\left[\frac{n_{2}}{k_{2}}\right]
$$

and the $\eta_{l}$ are one of the numbers $\alpha_{m_{1} m_{2} i j}$ with $m_{i}<\left[n_{i} / k_{i}\right](i=1,2)$.

Using (16), (17) and (18) one can easily show that for each summand in (22)

$$
\begin{aligned}
& \overline{\left|I_{l} \gamma_{l} \eta_{l}\right|}<\prod_{i=1}^{2}\left(\left[\frac{n_{i}}{k_{i}}\right]^{k_{i}+2}\left[\frac{n_{i}}{k_{i}}\right] ! M_{i}^{\lambda_{i}\left[n_{i} / k_{i}\right]} c^{\lambda_{i}\left[n_{i} / k_{i}\right]}\right. \\
& \left.O\left((A+\varepsilon)^{n_{i}} n_{i}^{s} i^{n_{i}}\right) O\left((B+\varepsilon)^{n_{i}} n_{i}^{t_{i} n_{i}}\right)\right) .
\end{aligned}
$$

The number of summands in (22) does not exceed $\prod_{i=1}^{2} k_{i}\left[n_{i} / k_{i}\right]$ and hence (23) implies

$$
\begin{aligned}
& \overline{\left|c_{n_{1} n_{2}}\right|}<\prod_{i=1}^{2}\left(\left[\frac{n_{i}}{k_{i}}\right]^{k_{i}+3} c^{\lambda_{i}\left[n_{i} / k_{i}\right]}\left[\frac{n_{i}}{k_{i}}\right] ! M_{i}^{\lambda_{i}\left[n_{i} / k_{i}\right]}\right. \\
& \left.O\left((A+\varepsilon)^{n_{i}} n_{i}^{s_{i} n_{i}}\right) O\left((B+\varepsilon)^{n_{i}} n_{i}^{t_{i} n_{i}}\right)\right) .
\end{aligned}
$$

Using (4), (19), (20), (21) and (24) we obtain for any $\varepsilon>0$.

$$
\begin{aligned}
\mid \text { Norm } c_{n_{1} n_{2}} \mid \leqq & \left.\left|c_{n_{i} n_{2}}\right| \overline{c_{n_{1} n_{2}}}\right|^{(d-1)} \\
\leqq & \prod_{i=1}^{2}\left(\left|V_{i}\right|^{2\left[n_{i} / k_{i}\right]}\left[\frac{n_{i}}{k_{i}}\right] ! n_{i}^{-n_{i} /\left(\rho_{i}+\varepsilon\right)} O\left((B+\varepsilon)^{n_{i}} n_{i}^{t_{i} n_{i}} c^{\lambda_{i}\left[n_{i} / k_{i}\right] d}\right)\right. \\
& \cdot\left([ \frac { n _ { i } } { k _ { i } } ] ^ { k _ { i } + 3 } [ \frac { n _ { i } } { k _ { i } } ] ! M _ { i } ^ { \lambda _ { i } [ n _ { i } / k _ { i } ] } \left(O\left((A+\varepsilon)^{n_{i}} n_{i}^{s_{i} n_{i}}\right)\right.\right. \\
& \left.\left.\times O\left((B+\varepsilon)^{n_{i}} n_{i}^{t_{i} n_{i}}\right)\right)^{(d-1)}\right) .
\end{aligned}
$$

If $\rho_{i}<\rho_{i 0}$, then a simple calculation shows that the right side of (25) is less than 1 for sufficiently large $n_{1}+n_{2}$ and the desired conclusion follows in this case. Using (5), (19), (20), (21) and (24) one obtains similarly 


$$
\begin{aligned}
& \left|\operatorname{Norm} c_{n_{1} n_{2}}\right| \leqq \prod_{i=1}^{2}\left(\left|V_{i}\right|^{2\left[n_{i} / k_{i}\right]}\left[\frac{n_{i}}{k_{i}}\right] !\left(e \rho_{i}\left(\sigma_{i}+\varepsilon\right) / n_{i}\right)^{n_{i} / \rho_{i}}\right. \\
& O\left((B+\varepsilon)^{n_{i}} n_{i}^{t_{i} n_{i}}\right) c^{\lambda_{i} d\left[n_{i} / k_{i}\right]}\left(\left[\frac{n_{i}}{k_{i}}\right]^{k_{i}+3}\left[\frac{n_{i}}{k_{i}}\right] ! M_{i}^{\lambda_{i}\left[n_{i} / k_{i}\right]}\right. \\
& \left.\left.O\left((A+\varepsilon)^{n_{i}} n_{i}^{s_{i} n_{i}}\right) O\left((B+\varepsilon)^{n_{i}} n_{i}^{t_{i} n_{i}}\right)\right)^{(d-1)}\right) .
\end{aligned}
$$

If $\rho_{i} \leqq \rho_{i 0}, i=1,2$ and $\rho_{i}=\rho_{i 0}, \sigma_{i}<\sigma_{i 0}$ for at least one of the $i$, then again a simple calculation shows that the right side of (26) is less than 1 for $n_{1}+n_{2}$ sufficiently large and the theorem follows.

The question of generalizing the results of one variable to functions which are not entire, such as meromorphic functions, has already been suggested by Straus [7]. More generally it would be interesting to consider meromorphic functions of several complex variables. Though it is difficult to see how the methods of this paper can be applied to this more general case, even with the aid of Nevanlinna theory, it is quite possible that other methods, such as for example the one used in the proof of Theorem 2 in [4], might yield interesting analogues of our results in the meromorphic case.

\section{BIBLIOGRAPHY}

1. R. C. Buck, Integral valued entire functions, Duke Math. J. 15 (1948), 879.

2. F. Gross, Generalized Taylor series and orders and types of entire functions of several complex variables, Trans. Amer. Math. Soc. 120 (1965) 124.

3. S. Kakeya, Notes on the maximum modulus of a function, Tohoku Math. J. 10 (1916), 68.

4. S. Lang, Introduction to transcendental numbers, Addison Wesley Reading, Mass., 1966.

5. A. Selberg, Über Einen Satz Von A Gelfand, Arch. Math. Naturvid 44 (1941), 159.

6. D. Sato and E. G. Straus, On the rate of growth of Hurwitz entire functions, J. Math. Soc. Japan, 1962.

7. E. G. Straus, On entire functions with algebraic derivatives at certain algebraic points, Ann. of Math. 52 (1950), 188.

Received November 24, 1965, in revised form June, 1969.

U. S. Naval Research Laboratory

WASHINGTON, D. C.

AND

UNIVERSITY OF MARYLAND 



\title{
PACIFIC JOURNAL OF MATHEMATICS
}

\author{
EDITORS
}

\author{
H. ROYDEN \\ Stanford University \\ Stanford, California \\ RICHARD PIERCE \\ University of Washington \\ Seattle, Washington 98105
}

\author{
J. DUGUNDJI \\ Department of Mathematics \\ University of Southern California \\ Los Angeles, California 90007 \\ BASIL GORDON \\ University of California \\ Los Angeles, California 90024
}

\section{ASSOCIATE EDITORS}

E. F. BECKENBACH
B. H. NeumanN

F. WOLF
K. YoshidA

\section{SUPPORTING INSTITUTIONS}

\author{
UNIVERSITY OF BRITISH COLUMBIA \\ CALIFORNIA INSTITUTE OF TECHNOLOGY \\ UNIVERSITY OF CALIFORNIA \\ MONTANA STATE UNIVERSITY \\ UNIVERSITY OF NEVADA \\ NEW MEXICO STATE UNIVERSITY \\ OREGON STATE UNIVERSITY \\ UNIVERSITY OF OREGON \\ OSAKA UNIVERSITY \\ UNIVERSITY OF SOUTHERN CALIFORNIA
}

\author{
STANFORD UNIVERSITY \\ UNIVERSITY OF TOKYO \\ UNIVERSITY OF UTAH \\ WASHINGTON STATE UNIVERSITY \\ UNIVERSITY OF WASHINGTON

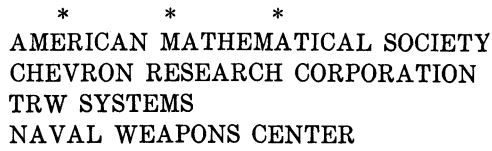

The Supporting Institutions listed above contribute to the cost of publication of this Journal, but they are not owners or publishers and have no responsibility for its content or policies.

Mathematical papers intended for publication in the Pacific Journal of Mathematics should be in typed form or offset-reproduced, double spaced with large margins. Underline Greek letters in red, German in green, and script in blue. The first paragraph or two must be capable of being used separately as a synopsis of the entire paper. It should not contain references to the bibliography. Manuscripts, in duplicate if possible, may be sent to any one of the four editors. Please classify according to the scheme of Math. Rev. 36, 1539-1546. All other communications to the editors should be addressed to the managing editor, Richard Arens, University of California, Los Angeles, California, 90024.

50 reprints are provided free for each article; additional copies may be obtained at cost in multiples of 50 .

The Pacific Journal of Mathematics is published monthly. Effective with Volume 16 the price per volume (3 numbers) is $\$ 8.00$; single issues, $\$ 3.00$. Special price for current issues to individual faculty members of supporting institutions and to individual members of the American Mathematical Society: $\$ 4.00$ per volume; single issues $\$ 1.50$. Back numbers are available.

Subscriptions, orders for back numbers, and changes of address should be sent to Pacific Journal of Mathematics, 103 Highland Boulevard, Berkeley, California, 94708.

PUBLISHED BY PACIFIC JOURNAL OF MATHEMATICS, A NON-PROFIT CORPORATION

Printed at Kokusai Bunken Insatsusha (International Academic Printing Co., Ltd.), 7-17, Fujimi 2-chome, Chiyoda-ku, Tokyo, Japan. 


\section{Pacific Journal of Mathematics}

\section{Vol. 31, No. $3 \quad$ BadMonth, 1969}

George E. Andrews, On a calculus of partition functions .................. 555

Silvio Aurora, A representation theorem for certain connected rings ............ 563

Lawrence Wasson Baggett, A note on groups with finite dual spaces ............. 569

Steven Barry Bank, On majorants for solutions of algebraic differential equations in regions of the complex plane ............................... 573

Klaus R. Bichteler, Locally compact topologies on a group and the corresponding continuous irreducible representations ......................... 583

Mario Borelli, Affine complements of divisors ....................... 595

Carlos Jorge Do Rego Borges, A study of absolute extensor spaces ............. 609

Bruce Langworthy Chalmers, Subspace kernels and minimum problems in Hilbert

spaces with kernel function ...................................... 619

John Dauns, Representation of L-groups and F-rings................. 629

Spencer Ernest Dickson and Kent Ralph Fuller, Algebras for which every

indecomposable right module is invariant in its injective envelope ...........

Robert Fraser and Sam Bernard Nadler, Jr., Sequences of contractive maps and fixed

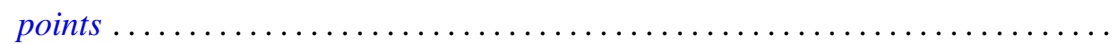

Judith Lee Gersting, A rate of growth criterion for universality of regressive

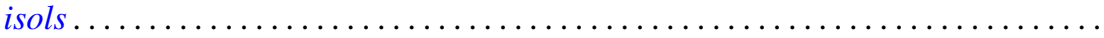

Robert Fred Gordon, Rings in which minimal left ideals are projective ............

Fred Gross, Entire functions of several variables with algebraic derivatives at certain algebraic points

W. Charles (Wilbur) Holland Jr. and Stephen H. McCleary, Wreath products of ordered permutation groups .........................

W. J. Kim, The Schwarzian derivative and multivalence .................. 717

Robert Hamor La Grange, Jr., On $(\mathrm{m}-\mathrm{n})$ products of Boolean algebras ......... 725

Charles D. Masiello, The average of a gauge ........................ 733

Stephen H. McCleary, The closed prime subgroups of certain ordered permutation

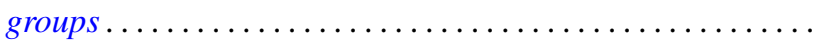

Richard Roy Miller, Gleason parts and Choquet boundary points in convolution measure algebras ...............................

Harold L. Peterson, Jr., On dyadic subspaces ........................ 773

Derek J. S. Robinson, Groups which are minimal with respect to normality being intransitive........................................... 777

Ralph Edwin Showalter, Partial differential equations of Sobolev-Galpern type . . . 787

David Slepian, The content of some extreme simplexes ................... 795

Joseph L. Taylor, Noncommutative convolution measure algebras ............. 809

B. S. Yadav, Contractions of functions and their Fourier series ............... 827

Lindsay Nathan Childs and Frank Rimi DeMeyer, Correction to automorphisms of separable algebras" ....................... 833

Moses Glasner and Richard Emanuel Katz, Correction to: "Function-theoretic degeneracy criteria for Riemannian manifolds".............

Satish Shirali, Correction to: "On the Jordan structure of complex Banach

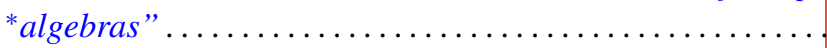

